\title{
Active-Site Modulation in an Fe-Porphyrin-Based Metal- Organic Framework through Ligand Axial Coordination: Accelerating Electrocatalysis and Charge-Transport Kinetics
}

Itamar Liberman ${ }^{\ddagger}$, Ran Shimoni ${ }^{\ddagger}$, Raya Ifraemov, Illya Rozenberg, Chanderpratap Singh, Idan $\operatorname{Hod}^{*}$

Department of Chemistry and Ilse Katz Institute for Nanoscale Science and Technology, Ben-Gurion University of the Negev, Beer-Sheva, 8410501, Israel. 


\section{Experimental section:}

The chemicals: zirconium (IV) chloride $\left(\mathrm{ZrCl}_{4} \geq 99.5 \%\right)$, terephthalic acid $\left(\mathrm{C}_{6} \mathrm{H}_{4}\left(\mathrm{CO}_{2} \mathrm{H}\right)_{2} \geq 98 \%\right)$, lithium perchlorate $\left(\mathrm{LiClO}_{4}, \geq 95 \%\right.$ ), 2- methyl imidazole (MeIM, $\left.\mathrm{C}_{6} \mathrm{H}_{6} \mathrm{~N}_{2}, 99 \%\right)$, Nafion perfluorinated solution (5 wt \%), deuterium oxide $\left(\mathrm{D}_{2} \mathrm{O} 99.9 \%\right)$ and ferrocene $\left(\mathrm{Fe}\left(\mathrm{C}_{5} \mathrm{H}_{5}\right)_{2}, 98 \%\right)$ were purchased from Sigma-Aldrich. Hemin(chloride) $\left(\mathrm{C}_{34} \mathrm{H}_{32} \mathrm{ClFeN}_{4} \mathrm{O}_{4}, \geq 98 \%\right)$ was purchaced from Carl Roth. Dimethylformamide (DMF, $\left.\mathrm{C}_{3} \mathrm{H}_{7} \mathrm{NO}\right)$, Sodium hydroxide $(\mathrm{NaOH}, \mathrm{AR})$ and hydrochloric acid $(\mathrm{HCl}, 32 \%)$ were purchased from Bio-Lab. Ethanol $\left(\mathrm{C}_{2} \mathrm{H}_{6} \mathrm{O}, 99.7 \%\right)$ and acetonitrile (HPLC) were purchased from J.T Baker. 1-Methyl-2-pyrrolidinone $\left(\mathrm{NMP}, \mathrm{C}_{5} \mathrm{H}_{9} \mathrm{NO}, 99.5 \%\right)$ and benzoic acid $\left(\mathrm{C}_{7} \mathrm{H}_{6} \mathrm{O}_{2}\right.$ ,99\%) were purchased from Acros Organic. Polyvinylidene fluoride was purchased from Alfa Aesar. Tetrabutylammonium Hexafluorophosphate $\left(\mathrm{TBAPF}_{6}, \mathrm{C}_{16} \mathrm{H}_{36} \mathrm{~F}_{6} \mathrm{NP},>98.0 \%\right)$ was purchased from TCI. Nitric acid (7o\%) and glacial acetic acid were purchased from Daejung. Oxygen gas $\left(\mathrm{O}_{2}, \geq 98 \%\right)$ was purchased from Maxima.

UIO-66 Synthesis: $\mathrm{ZrCl}_{4}(125 \mathrm{mg}$, $0.45 \mathrm{mmol}$ ) was dissolved in the mixture of $5 \mathrm{ml}$ of DMF and $1 \mathrm{ml}$ of $\mathrm{HCl}$ (assisted by sonication). After the complete dissolving, $123 \mathrm{mg}(0.75 \mathrm{mmol})$ of terephthalic acid and $10 \mathrm{ml}$ of DMF were added to the mixture. A glass vial with the mixture was heated at $70^{\circ} \mathrm{C}$ inside the oven overnight. The as-prepared UIO-66 was isolated by centrifugation and washed three times with DMF and three times with ethanol. Then the synthesized material was dried in the vacuum oven at $70^{\circ} \mathrm{C}$ overnight.

Post-synthetic modification of UIO-66 with Hemin: $34 \mathrm{mg}$ (0.054 mmol) of Hemin were added to $10 \mathrm{ml}$ of DMF containing $200 \mathrm{mg}$ of UIO-66 powder. The suspension was heated at $70^{\circ} \mathrm{C}$ inside the oven overnight. UIO-66@Hemin was isolated from the solution by centrifugation and washed three times with DMF (or until the solvent was colorless) and three times with ethanol. The product was dried in the vacuum oven at $70^{\circ} \mathrm{C}$ overnight.

Glassy carbon-based electrodes preparation: $30 \mathrm{mg}$ of UIO-66 or UIO-66@Hemin were mixed with 1 ml of NMP and $3 \mathrm{mg}$ of polyvinylidene fluoride and stirred overnight with magnetic stirrer. For the rotating disk electrode (RDE) and rotating ring disk electrode (RRDE) $1 \mu \mathrm{l}$ and $2.8 \mu$ (respectively) of this ink were drop-casted on glassy carbon surfaces of the electrodes and dried at $70^{\circ} \mathrm{C}$ in the oven for at least one hour. Then the UIO-66 and UIO-66@Hemin glassy carbon electrodes were used as the working electrodes for the oxygen reduction reaction (ORR) in the various electrochemical measurements.

Carbon cloth based UIO-66@Hemin electrode preparation: 30 mg of UIO-66@Hemin were homogeneously dispersed in the solvents mixture of $0.75 \mathrm{ml}$ ultra-pure water, $0.25 \mathrm{ml}$ of isopropyl alcohol and $60 \mu \mathrm{l}$ of Nafion solution by ultra-sonication until the homogeneous ink was obtained. Then the carbon cloth was coated via drop-casting method with small portions of this ink up to $166 \mu \mathrm{l}$ in total or $5 \mathrm{mg} / \mathrm{cm}^{2}$ loading after drying on air. The carbon-cloth UIO-66@Hemin electrode was directly used as a working electrode for the suitable electrochemical experiments.

Electrochemical characterization: Three-electrode cell was used for electrochemical measurements. Ag wire and Pt foil (with active area of $1 \mathrm{~cm}^{2}$ ) were used as a quasi-reference and a counter electrode respectively. UIO-66@Hemin carbon-cloth electrode was used as a working electrode (active area of $1 \mathrm{~cm}^{2}$ ). The data was recorded with Bio-Logic VSP instrument. Prior to each measurement the electrolyte solution (o.1 M lithium perchlorate in acetonitrile) was purged with argon for $20 \mathrm{~min}$. All cyclic voltammograms are reported versus $\mathrm{Fc} / \mathrm{Fc}^{+}\left(\mathrm{E}_{\mathrm{V} v \mathrm{Fsc} \backslash \mathrm{Fc}^{+}}=\mathrm{E}_{\mathrm{Ag} \backslash \mathrm{Ag}}{ }^{+}+\mathrm{E}_{\mathrm{Fc} \backslash \mathrm{Fc}}(\mathrm{V} v \mathrm{sg} \mathrm{Ag})\right.$ and were conducted at $100 \mathrm{mV} / \mathrm{sec}$ scan rate. For the experiments with varying 2-methyl imidazole (MeIM) 
concentrations, an appropriate amount of $0.1 \mathrm{M}$ MeIM in acetonitrile solution was added to attain $0,0.1,0.2,0.3,0.4$, $0.5,1,2$, and $2.5 \mathrm{mM}$ concentrations of MeIM in the cell. The solution was purged again for 7 min with argon to remove any oxygen from the reaction mixture. Potential-step chronoamperometry measurements were carried with the same MeIM concentrations as described above and the voltage was stepped from $0.15 \mathrm{~V}$ to $-0.45 \mathrm{~V}$ (vs $\mathrm{Fc} / \mathrm{Fc}^{+}$).

Electrochemical oxygen reduction reaction (ORR) measurements: UIO-66 and UIO-66@Hemin were deposited by drop-casting on glassy carbon RDE ( $0.3 \mathrm{~cm}$ in diameter) and RRDE ( $0.5 \mathrm{~cm}$ in diameter glassy carbon disc and Pt ring) by the method described above. The electrochemical experiments of ORR were conducted with PGSTAT AUTOLAB setup when the RDE and RRDE electrodes used as working electrodes, Ag wire as quasi-reference electrode and Pt foil (with active area of $1 \mathrm{~cm}^{2}$ ) as counter electrode. For all the experiments the electrolyte solution (o.1 $\mathrm{M}$ lithium perchlorate in $90 \% \mathrm{v} / \mathrm{v}$ acetonitrile/ $10 \% \mathrm{v} / \mathrm{v}$ water) was bubbled with $\mathrm{O}_{2}$ for 20 min and gentle oxygen bubbling was maintained during each measurement.

For the ORR CV experiments the RDE rotation speed was kept constant at 1200 rpm and the different MeIM concentrations (o, o.1, o.2, 0.5, 1, 2, and $2.5 \mathrm{mM}$ ) were achieved by the same method as described above. The voltage was scanned cathodically from $0.456 \mathrm{~V}$ to $-1.244 \mathrm{~V}$ (vs NHE) at $100 \mathrm{mV} / \mathrm{s}$ scan rate. The solution was bubbled with oxygen gas for 7 min between each measurement to ensure saturation of the oxygen in the solution.

For the different rotation speed experiments several rpm speeds were selected (100-1000 rpm in 50 rpm steps, followed by 1100, 1200, 1300, 1400, 1500, 2000, 2500, and 3000 rpm). Prior to each step the solution was bubbled with oxygen gas for 5 min to ensure saturation of the oxygen in the solution. The linear sweep voltammetry was done in the range from $0.2 \mathrm{~V}$ to $-1.2 \mathrm{~V}$ vs. Ag at $5 \mathrm{mV} / \mathrm{s}$ scan rate.

For the RRDE experiments the rotation speed was kept constant at $1600 \mathrm{rpm}$ and the ring potential was held at $0.75 \mathrm{~V}$ (vs NHE). The linear sweep voltammetry from $0.75 \mathrm{~V}$ to $-1 \mathrm{~V}$ (vs NHE) at $5 \mathrm{mV} / \mathrm{s}$ scan rate, was applied over the disk electrode. Prior to the measurement the electrolyte solution was bubbled with oxygen gas for 20 min. The experiments with different MeIM concentrations (0.1, 0.2, 0.3, 0.5, 1, 1.5, and $2 \mathrm{mM}$ ) were conducted by the same method described above. The solution was bubbled with oxygen gas for 7 min between each measurement to ensure oxygen saturation in solution.

The number of the transferred electrons (in the RRDE experiment) was calculated by the following equation S1

$$
\text { Number of transferred electrons }=\frac{\left(i_{D}-\frac{i_{R}}{N}\right)}{i_{D}} \times W P+\frac{i_{R}}{N \times i_{D}} \times P P
$$

where $i_{D}$ is the glassy carbon disk electrode current, $i_{R}$ is the current on the Pt ring and $N$ is the theoretical collection efficiency of the RRDE system. PP and WP are the number of the electrons transferred for $\mathrm{H}_{2} \mathrm{O}_{2}(2)$ and water $(4)$ production, respectively.

The production of $\mathrm{H}_{2} \mathrm{O}_{2}$ in the ORR was calculated as percentage by equation $\mathrm{S}_{2}$

$$
\% \mathrm{H}_{2} \mathrm{O}_{2}=\frac{\mathrm{i}_{\mathrm{R}}}{\mathrm{N} \times \mathrm{i}_{\mathrm{D}}} \times 100
$$


where $\mathrm{i}_{R}, \mathrm{i}_{\mathrm{D}}$ and $\mathrm{N}$ have the same meaning as in the equation S1. For all the experiments in this section the potential is reported versus normal hydrogen electrode $\left(\mathrm{NHE} ; \mathrm{E}_{\mathrm{NHE}_{\mathrm{Acetonitrile}}}=\mathrm{E}_{\mathrm{Ag}}+0.63-\mathrm{E}_{\mathrm{Fc} \backslash \mathrm{Fc}^{+}}(\mathrm{V} v \mathrm{Ag})\right)^{1}$.

All currents in this section were normalized to an active surface area of $1 \mathrm{~cm}^{2}$ depending on the electrode diameter.

MeIM axial coordination: A UIO-66@Hemin powder (100 mg) was soaked in $10 \mathrm{ml}$ of o.1 M MeIM solution in acetonitrile and stirred on magnetic plate overnight. Then the powder was separated by the centrifugation and dried in the vacuum oven. The dry UIO-66@Hemin (o.1 M MeIM) was characterized by X-ray photoelectron spectroscopy (XPS) and electron paramagnetic resonance (EPR). For the Raman spectroscopy measurements UIO-66@Hemin was wetted with o.1 M MeIM solution in acetonitrile and dried in air before the measurement.

ORR stability measurement: UIO-66@Hemin ink was drop-casted on the carbon cloth electrode as described above. Three-electrode cell was used as described above (in section of Electrochemical characterization) with o.1M lithium perchlorate in $90 \% \mathrm{v} / \mathrm{v}$ acetonitrile / $10 \% \mathrm{v} / \mathrm{v}$ water, as electrolyte solution. The solution was bubbled with oxygen gas for $20 \mathrm{~min}$. For a chronoamperometry experiment, a potential of $-0.7 \mathrm{~V}$ (vs Ag) was applied for nine cycles of $30 \mathrm{~min}$ each in which gentle oxygen flow was maintained. Between each cycle the solution was bubbled with oxygen for 10 min. In the end, a 2 hours cycle was applied, making it either a total of 10 cycles or 7 h measurement. Then the carbon cloth electrode was washed with ethanol and examined by SEM and Raman spectroscopies.

Homogeneous catalysis by Hemin (control experiment): $1 \mathrm{mM}$ of Hemin was dissolved in DMF with $10 \% \mathrm{v} / \mathrm{v}$ water and o.1 M TBAPF6 as electrolyte. The experiment was done in the 1 compartment 3-electrode cell with following set of electrodes: a glassy carbon RDE with rotation speed of $1200 \mathrm{rpm}$ as a working electrode, Pt foil of $1 \mathrm{~cm}^{2}$ as a counter electrode and $\mathrm{Ag}$ wire as a quasi-reference electrode. $\mathrm{CV}$ under the oxygen environment was performed in two different concentrations of o and $8 \mathrm{mM}$ of MeIM.

\section{Physical methods:}

The crystalline structures of the as-prepared MOF's, UIO-66 and UIO-66@Hemin, were confirmed by X-ray diffraction using PAN alytical's Empyream multi-purpose diffractometer instrument and Cu-K $\alpha$ (o.15405 nm) radiation.

The scanning electron microscope (SEM) images were taken using Verios XHR 46oL SEM instrument operating at $2 \mathrm{kV}$ accelerating voltage.

The samples for determination of zirconium and iron concentrations were obtained by dissolving the UIO$66 @$ Hemin in concentrated nitric acid inside the autoclave and followed by heating to $130^{\circ} \mathrm{C}$ in the oven overnight. The samples were analyzed using Spectro ARCOS ICP-OES, FHX22 multi-View plasma (SOP, EOP) instrument.

The (XPS) spectra were collected using ESCALAB 250 apparatus X-ray photoelectron spectrometer, with Al-Ka X-ray source and monochromator. The survey spectra were recorded with a pass energy (PE) $150 \mathrm{eV}$ and the high energy resolution was achieved with PE of $20 \mathrm{eV}$. To correct the charging effect, all measured spectra were calibrated relatively to carbon is peak position at $284.8 \mathrm{eV}$ and the data processing was done with AVANTGE program. 
Raman spectroscopy measurements were done in Horiba LabRam HR evolution micro-Raman system, equipped with a Synapse Open Electrode CCD detector, air cooled to $-60{ }^{\circ} \mathrm{C}$. The excitation source was a $532 \mathrm{~nm}$ laser and it was focused with an x50 objective lens. The typical exposure time was 120-180 sec.

$\mathrm{N}_{2}$ physisorption isotherms for the UIO-66 and UIO-66@Hemin were measured in Quantachrome Autosorb IQ2 at $77 \mathrm{~K}$. The samples were degassed at $120^{\circ} \mathrm{C}$ in vacuum for $17 \mathrm{~h}$ before the measurement. The surface area of the samples was calculated by fitting the isotherm data point of the absorption branch to Brunauer-Emmett-Teller (BET) model and the pore size distribution by applying the Discrete Fourier transform-density theory (DFT) model to the isotherm.

Hydrogen Nuclear Magnetic Resonance (H-NMR) measurements were done on Bruker DPX 500 instrument. In order to evaluate the concentration of BDC, a calibration curve was done. The different concentrations of BDC were prepared in 1M NaOH/D2O . Then 1 mg of UIO-66 and UIO-66@Hemin were taken and dissolved in 33 NaOH/D2O, and then diluted to 1 M. For each NMR tube a known amount of acetic acid was added as internal standard.

EPR measurements were done using an EMX-220 X-band ( $v=9.4-9.8 \mathrm{GHz})$ spectrometer (Bruker Biospin, Rheinstetten, Germany), 


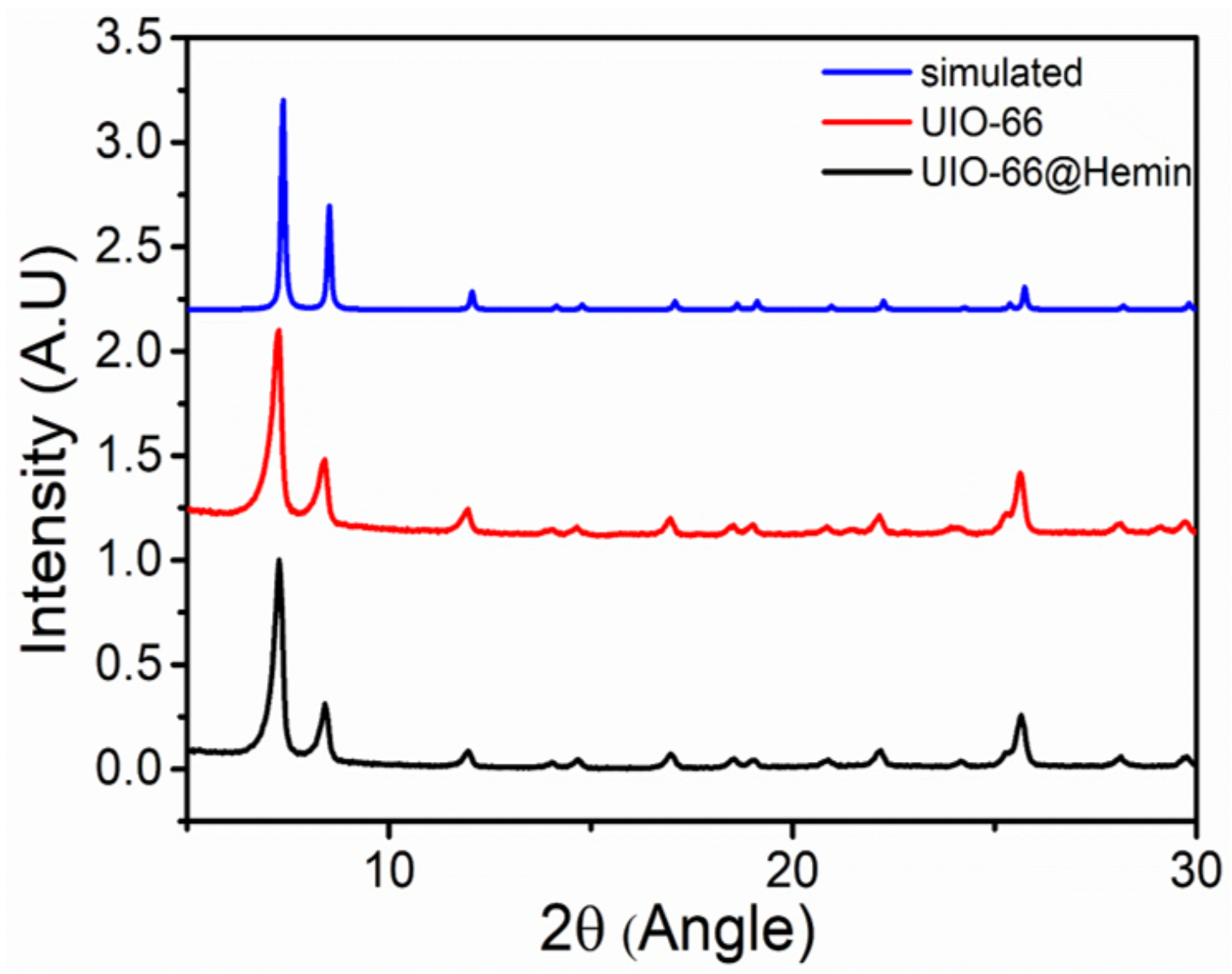

Figure S1. The XRD patterns of the simulated UIO-66 (blue) ${ }^{2}$, the as-prepared UIO-66 (red) and UIO-66@Hemin (black).

a)

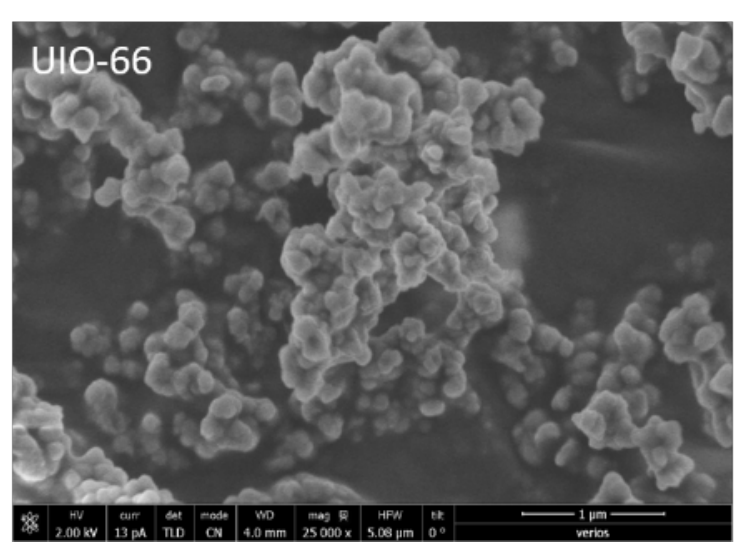

b)

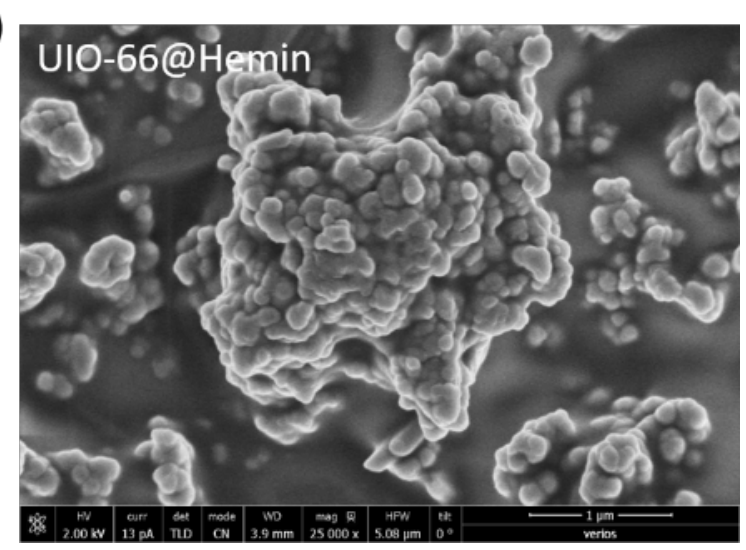

Figure S2. The SEM images of: a) UIO-66 and b) as-prepared UIO-66@Hemin. 
a)

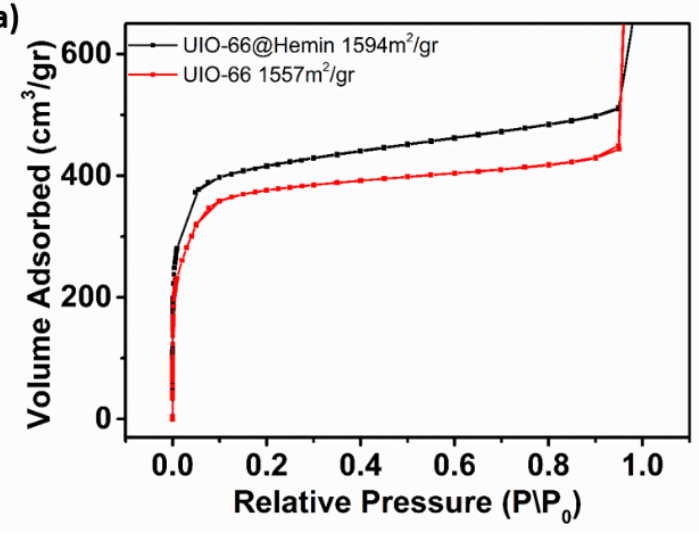

b)

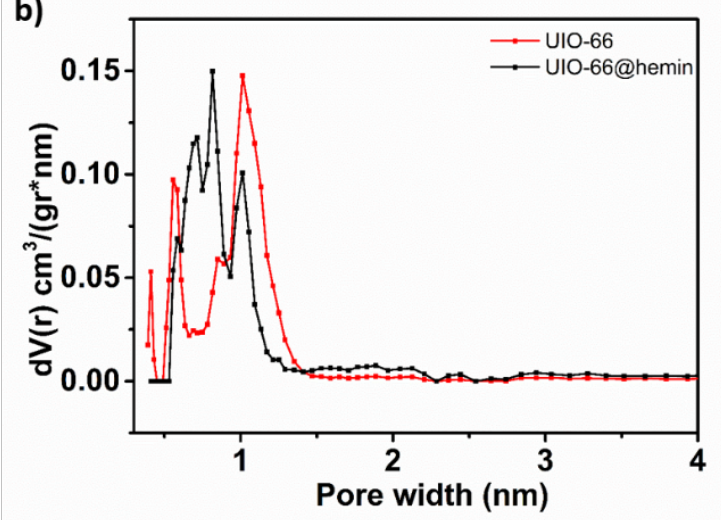

Figure $S_{3}$. a) The physisorption isotherms of the UIO-66 (red) and UIO-66@Hemin (black) and the surface areas of the MOFs, calculated from BET; b) the pore size distribution for the UIO-66 (red) and UIO-66@Hemin (black)

a)

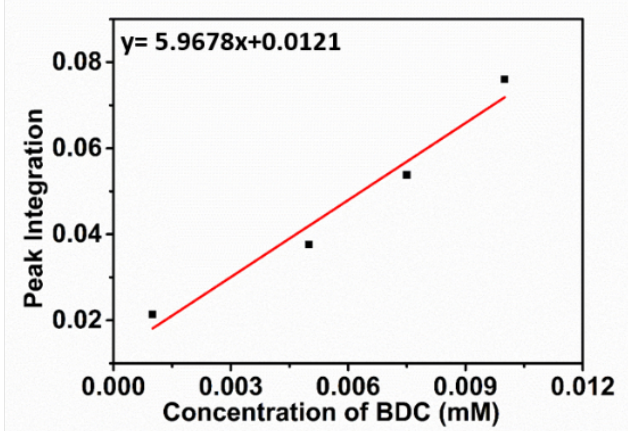

b)

\begin{tabular}{|c|c|c|c|c|c|c|}
\hline & $\begin{array}{c}\text { NMR } \\
\text { Integration }\end{array}$ & $\begin{array}{c}\text { BDC } \\
\text { Concentration } \\
\mathbf{m g / m o l}\end{array}$ & $\begin{array}{c}\text { ICP-OES Zr } \\
\mathbf{( m g / L )}\end{array}$ & $\begin{array}{c}\mathbf{Z r}_{\mathbf{6}} \\
\text { Concentration } \\
\mathbf{m g} / \mathbf{M o l}\end{array}$ & $\begin{array}{c}\text { Concentration } \\
\text { of BDC per } \mathbf{Z r}_{\mathbf{6}}\end{array}$ & $\begin{array}{c}\text { Number } \\
\text { of BDC per } \\
\mathbf{Z r}_{\mathbf{6}}\end{array}$ \\
\hline UIO-66 & 0.0369 & $1.92^{*} 10^{-6}$ & 96.48 & $4.30^{*} 10^{-7}$ & 4.46 & 8.92 \\
\hline UIO-66@Hemin & 0.0376 & $1.94 * 10^{-6}$ & 101.04 & $4.34 * 10^{-7}$ & 4.47 & 8.94 \\
\hline
\end{tabular}

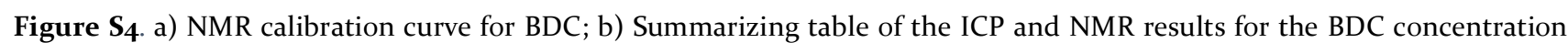
per $\mathrm{Zr}_{6}$.

\begin{tabular}{|c|c|c|c|c|c|}
\hline Sample & $\mathrm{Fe}$ & $\mathrm{Zr}$ & $\mathrm{Fe} / \mathrm{Zr}_{6}$ & $\mathrm{Zr}_{6 /} \mathrm{Fe}$ & $\begin{array}{c}\text { Hemin concentration } \\
{\left[\mathrm{mol} / \mathrm{cm}^{2}\right]}\end{array}$ \\
\hline UIO-66@Hemin & 1.297 & 31.432 & 0.248 & 4.039 & $3.740^{*} 10^{-7}$ \\
\hline
\end{tabular}

Table S1. The ICP elemental analysis characterization of UIO-66@Hemin, showing the $\mathrm{Zr}_{6}$-to-Fe molar ratio, as well as the calculated concentration of the Hemin loaded on the MOF. 


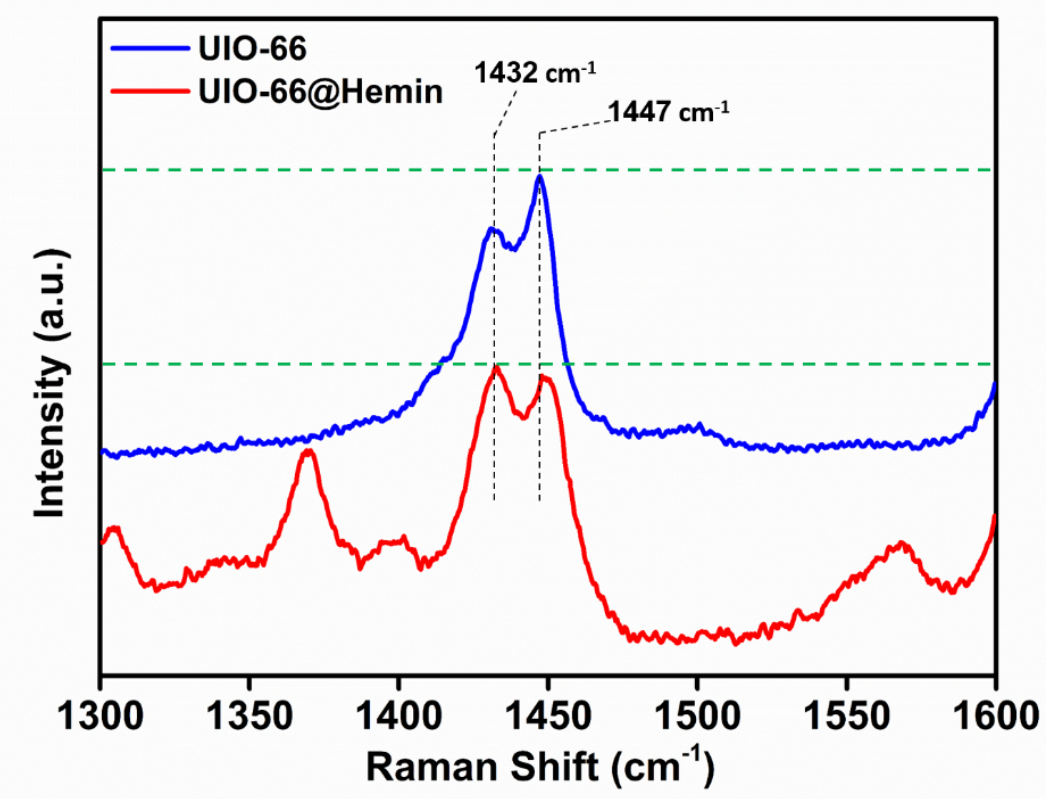

Figure S5. The Raman shift spectra of the UIO-66 (blue) and UIO-66@Hemin (red). The two peaks at 1369.5 and 1568 $\mathrm{cm}^{-1}$ are assigned to pyrrole half ring symmetric stretching, $v_{4}$ and $v_{2}$, of the Hemin (respectively), confirming its successful anchoring to the UIO-66.,4
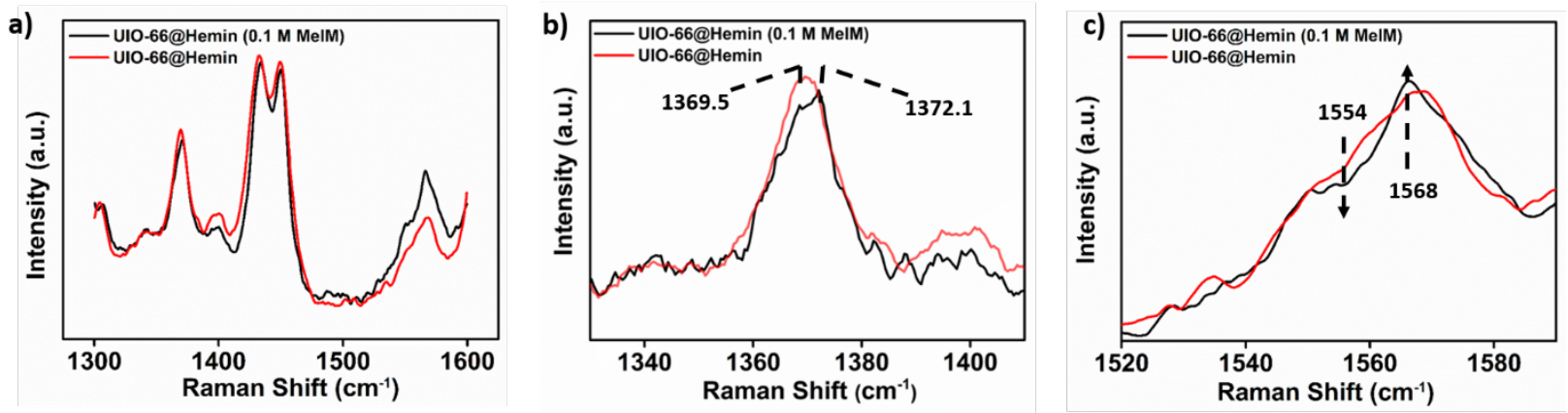

Figure S6. a) The Raman spectra of UIO-66@Hemin with (black) and without (red) MeIM; b) expansion of the pyrrole half ring stretching $v_{4}$ peak region. $c$ ) expansion of the pyrrole half ring stretching $v_{2}$ peak region.

The shift of the $v_{4}$ peak at $1369.5 \mathrm{~cm}^{-1}$ to a higher frequency of $1371.2 \mathrm{~cm}^{-1}$ indicates the axial coordination of MeIM to the Hemin, changing its spin property toward its low spin form. This conclusion is further supported by the change in the ratio between the peaks at $1554 \mathrm{~cm}^{-1}$ (high spin) and $1568 \mathrm{~cm}^{-1}$ (low spin), $v_{2}$ stretching in the UIO-66@Hemin ${ }^{4}$ 


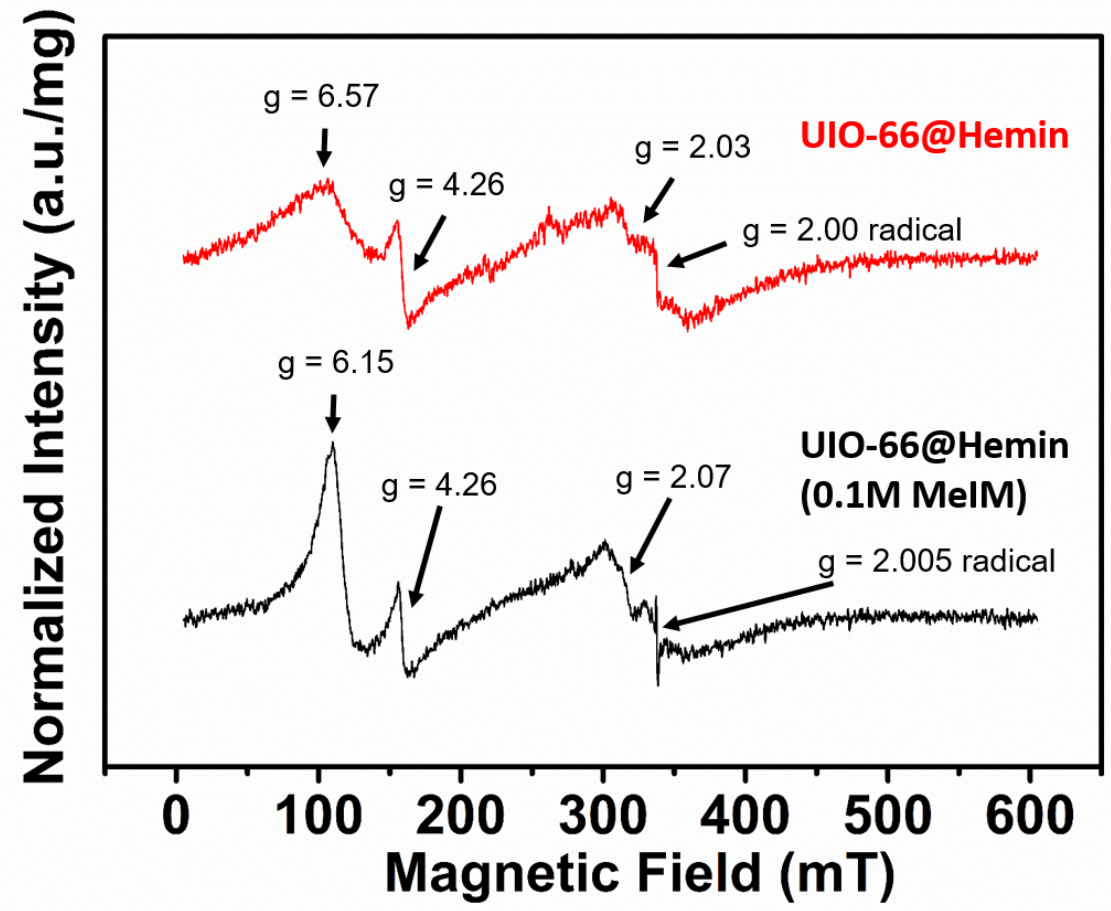

Figure S7. Comparative EPR measurements of UIO-66@Hemin and UIO-66@Hemin with o.1M MeIM. ${ }^{5}$

a)

XPS UIO66@Hemin

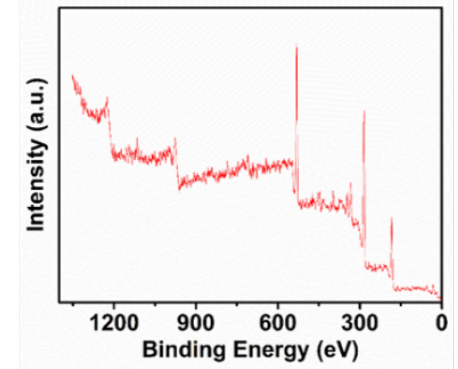

b)

XPS UIO66@Hemin (0.1M MelM)

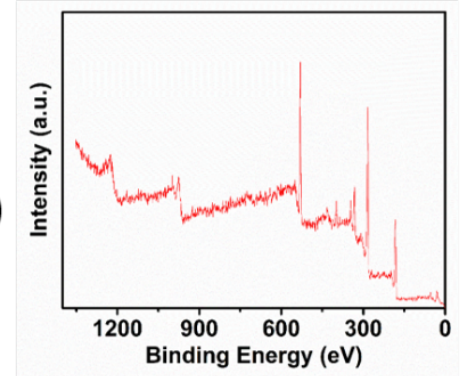

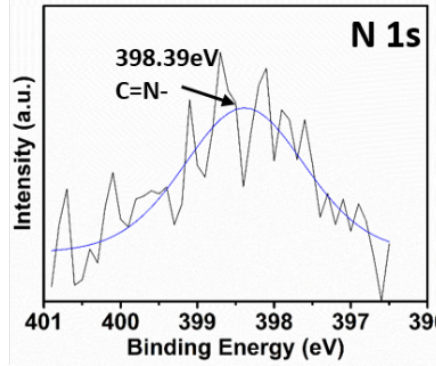
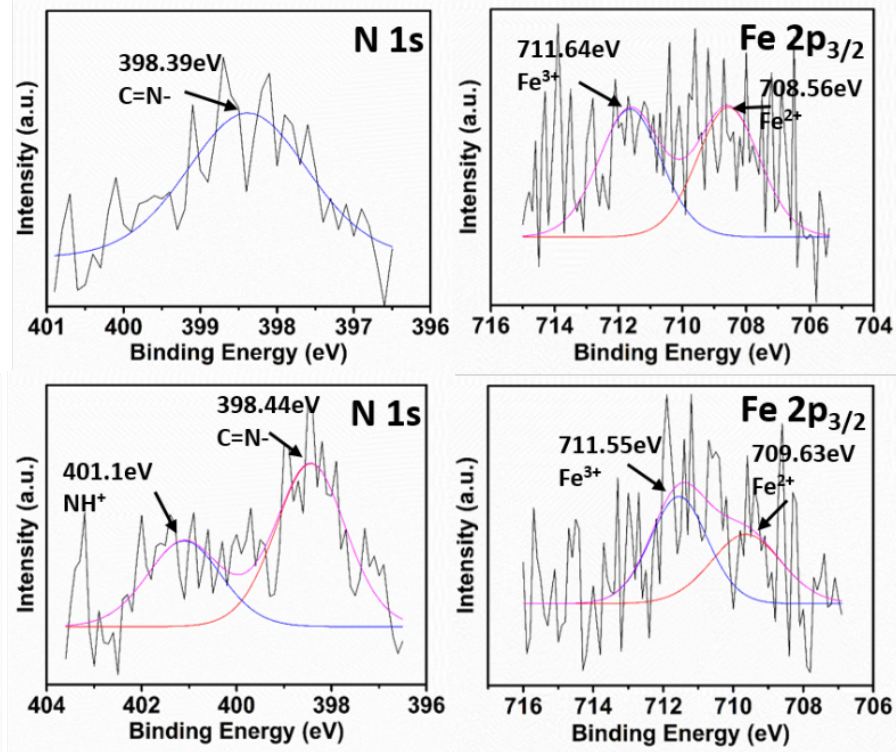

Figure S8. The XPS binding energy (BE) spectra of Fe and $\mathrm{N}$ atoms for the (a) UIO-66@Hemin and (b) UIO$66 @$ Hemin with 0.1 M MeIM. 

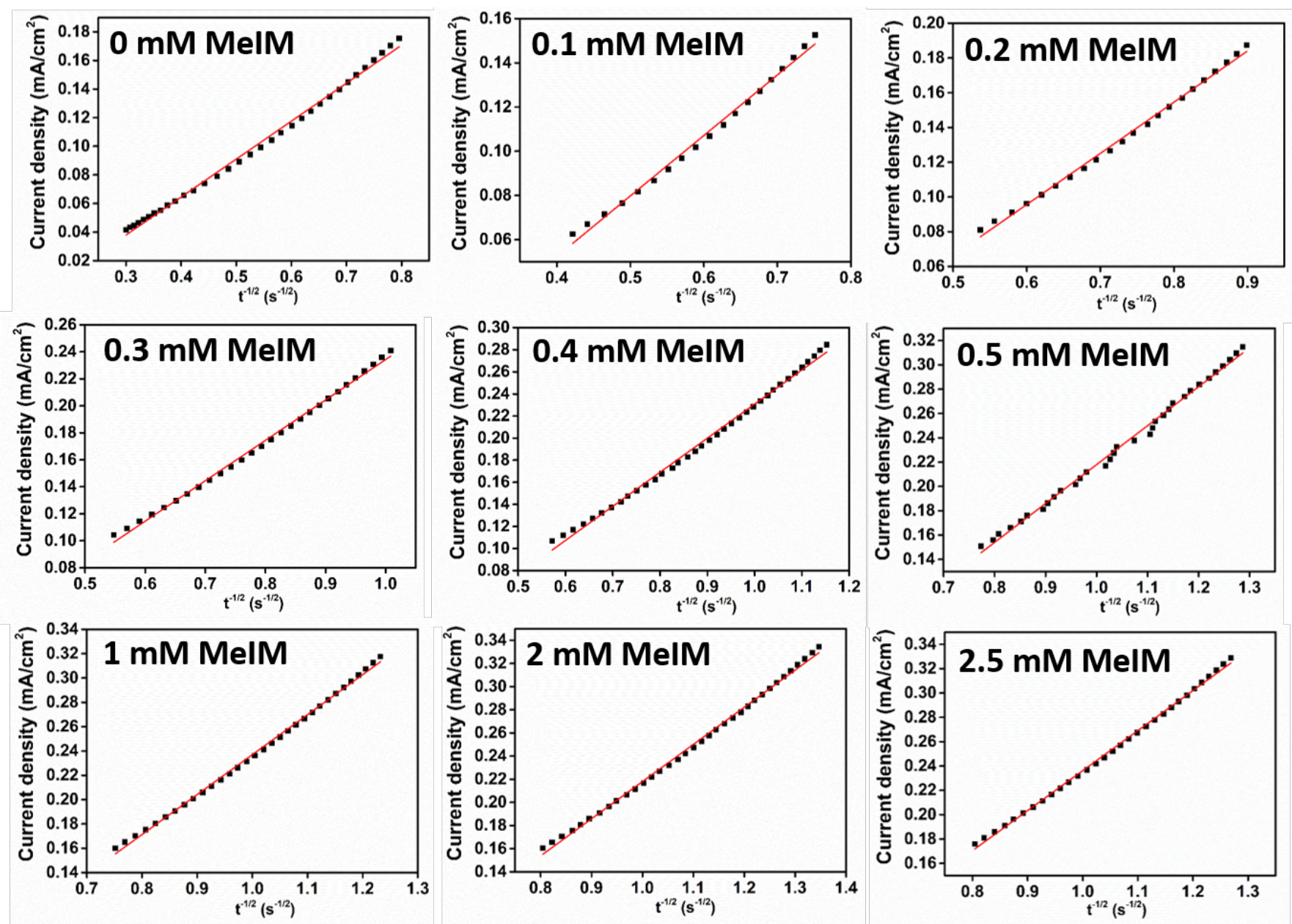

Figure S9. The Cottrell plots (current vs. square root of time) for the cathodic potential step measurements for UIO66@Hemin at different MeIM concentrations. 


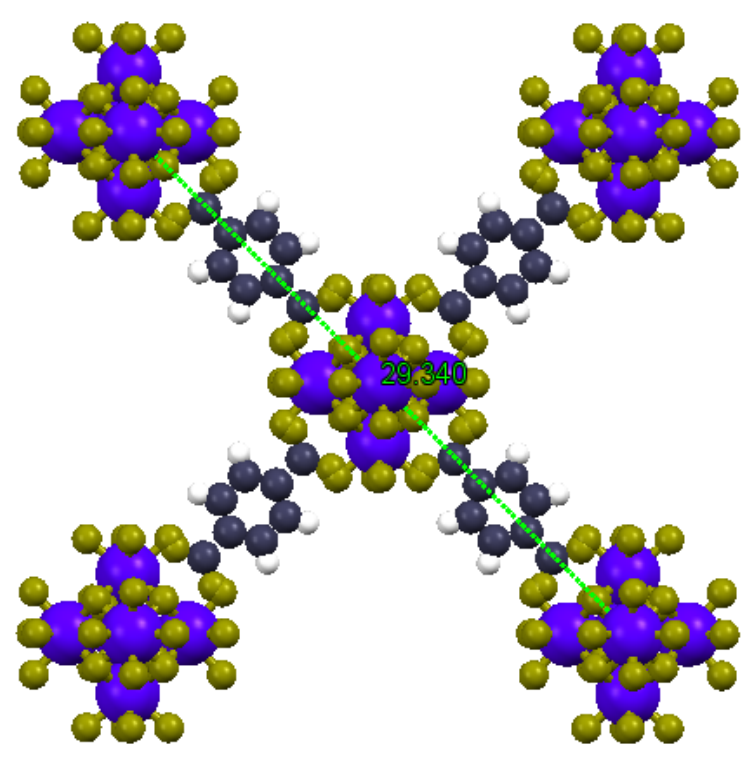

Figure S1o. The estimated distance between two adjacent Hemin moieties in UIO66@Hemin. It was estimated by taking into account the zirconium node/Hemin ratio of $4 / 1^{2}{ }^{2}$

\begin{tabular}{|c|c|c|c|}
\hline \multicolumn{5}{|c|}{ Slope $\begin{array}{c}\text { Dopping }{ }^{*} 10^{-10} \\
{\left[\mathrm{~cm}^{2} / \mathrm{s}\right]}\end{array}$} \\
\hline $\mathbf{0}$ & 0.26540 & 2.114 & 2513.8 \\
\hline $\mathbf{0 . 1}$ & 0.27374 & 2.250 & 2675.2 \\
\hline $\mathbf{0 . 2}$ & 0.29458 & 2.604 & 3096.9 \\
\hline $\mathbf{0 . 3}$ & 0.29938 & 2.690 & 3198.6 \\
\hline $\mathbf{0 . 4}$ & 0.30858 & 2.858 & 3398.3 \\
\hline $\mathbf{0 . 5}$ & 0.32006 & 3.075 & 3655.8 \\
\hline $\mathbf{1}$ & 0.32854 & 3.240 & 3852.1 \\
\hline $\mathbf{2}$ & 0.32104 & 3.093 & 3678.2 \\
\hline $\mathbf{2 . 5}$ & 0.32879 & 3.245 & 3858.0 \\
\hline
\end{tabular}

Table S2. Summary of $\mathrm{D}_{\text {hopping }}$ and $\mathrm{k}_{\text {hopping }}$ values calculated from the Cottrell equation for the UIO-66@Hemin in different (MeIm) concentrations. 


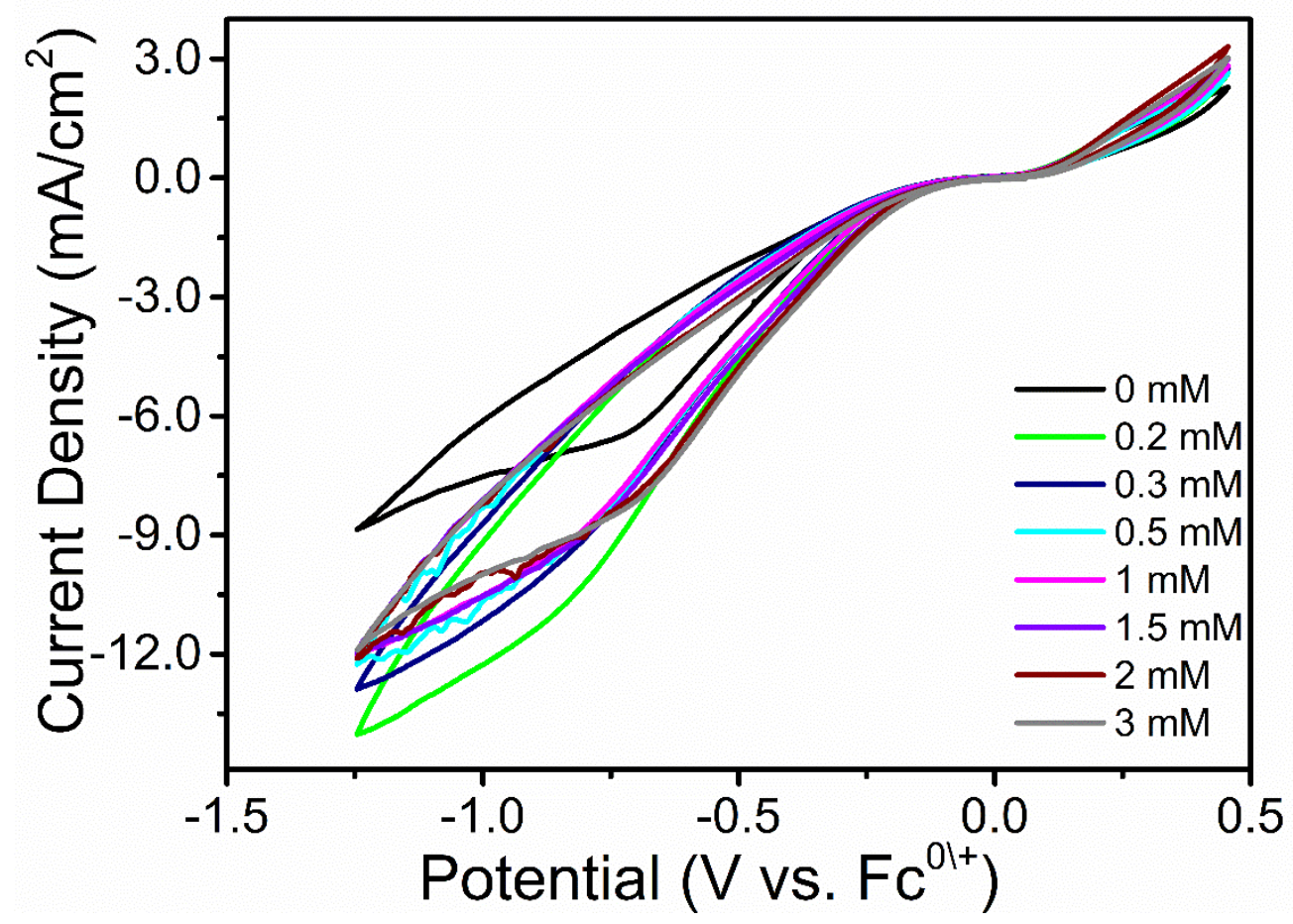

Figure S11. The cyclic voltammograms of bare UIO-66 under oxygen atmosphere at different MeIM concentrations (scan rate of $100 \mathrm{mV} / \mathrm{s}$ ).

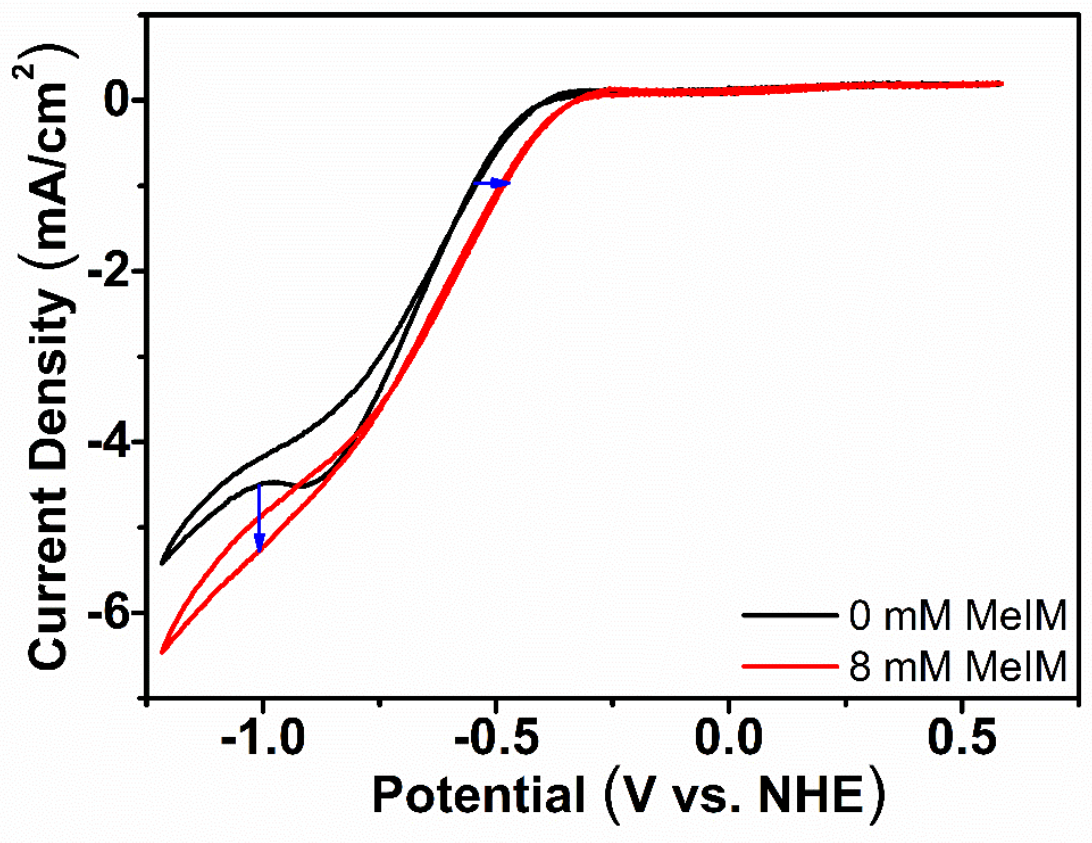

Figure S12. Cyclic voltammetry of Hemin homogeneous catalyst with (black) and without MeIM (red). The measurements were performed in $\mathrm{DMF}$ with o.1 $\mathrm{mM}_{\text {of }} \mathrm{TBAPF}_{6}$ as the supporting electrolite. 

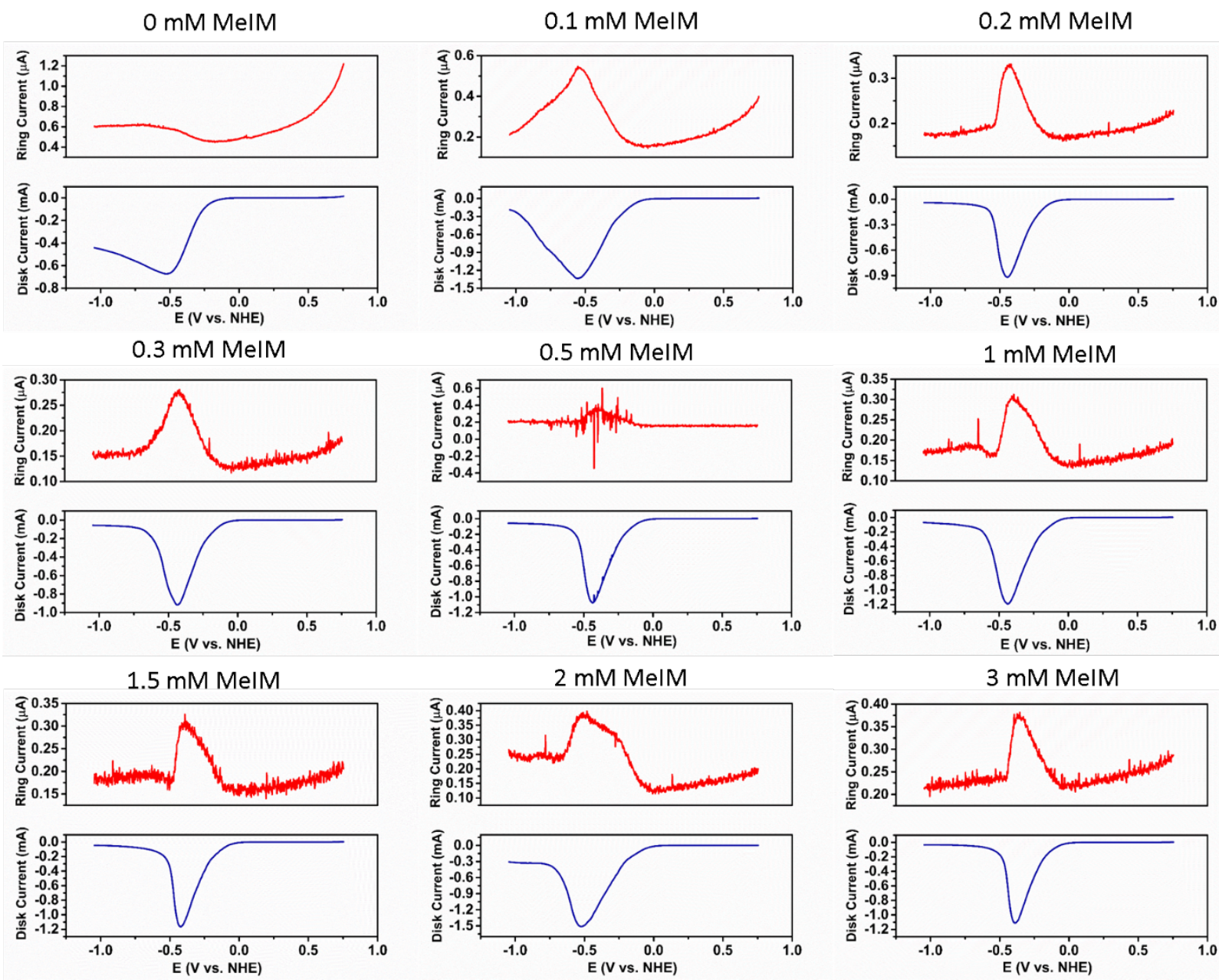

Figure S13. The RRDE experiments for the ORR with UIO-66@Hemin at different MeIM concentrations in the oxygen atmosphere. The disk potential was linearly scanned in the cathodic direction from $0.75 \mathrm{~V}$ to $-1 \mathrm{~V}$ (vs NHE) at $5 \mathrm{mV} / \mathrm{s}$ scan rate, while the ring potential was held constant at $0.75 \mathrm{~V}$ (vs NHE) to collect the $\mathrm{H}_{2} \mathrm{O}_{2}$ product. 

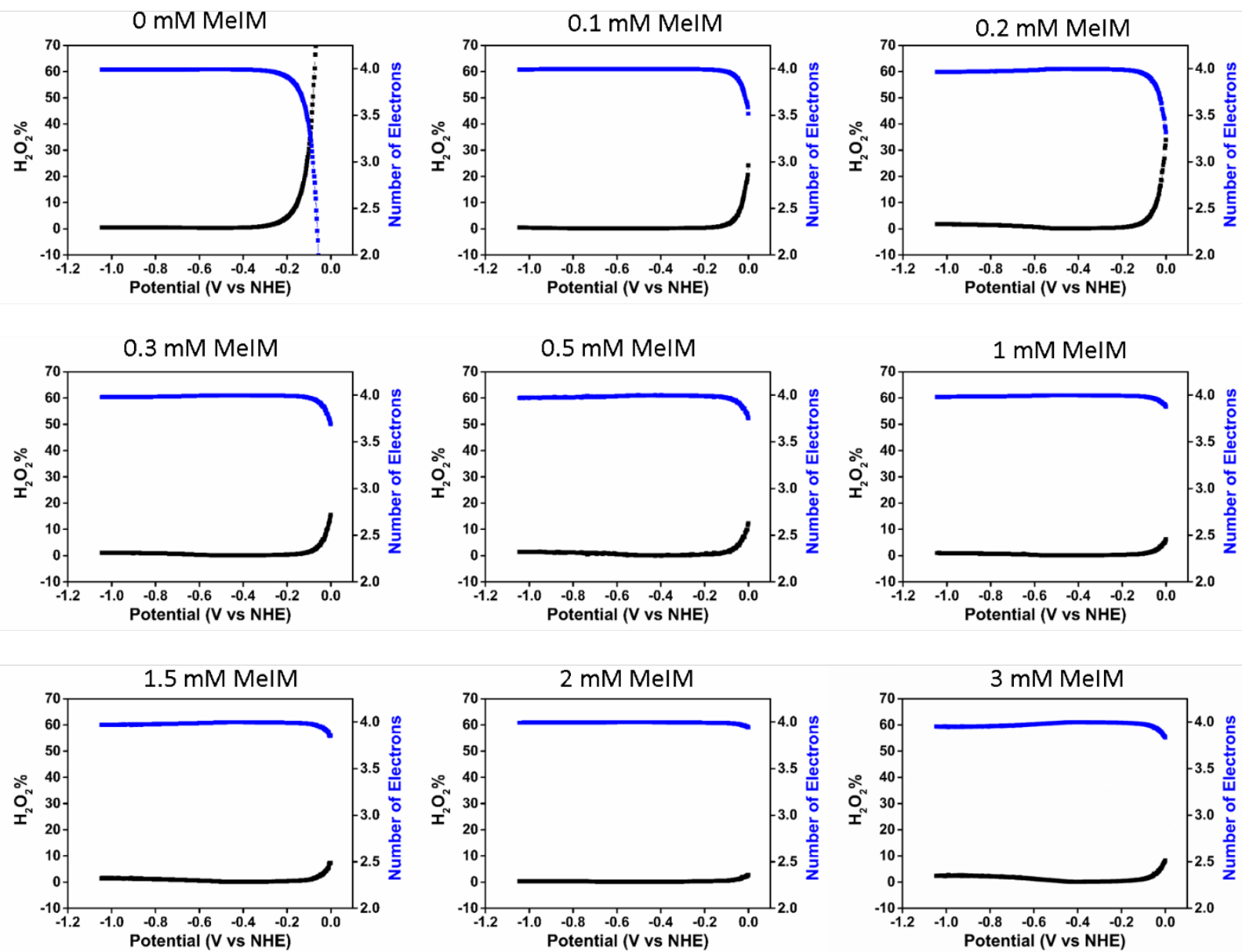

Figure S14. The calculated number of the transferred electrons (blue) and the $\mathrm{H}_{2} \mathrm{O}_{2}$ percentages (black) in ORR experiments with UIO-66@Hemin at different MeIM concentrations, elucidated from the RRDE results. 
$0 \mathrm{mM}$ MelM
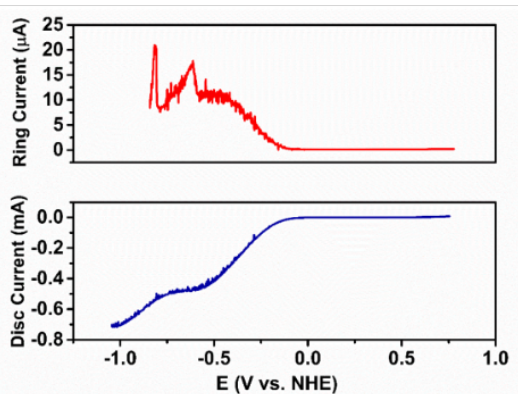

$0.5 \mathrm{mM}$ MelM
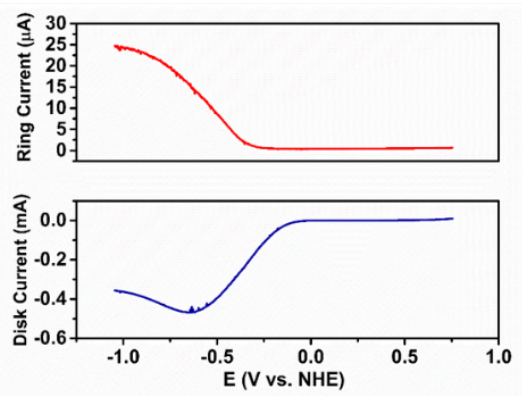

$0.1 \mathrm{mM}$ MelM
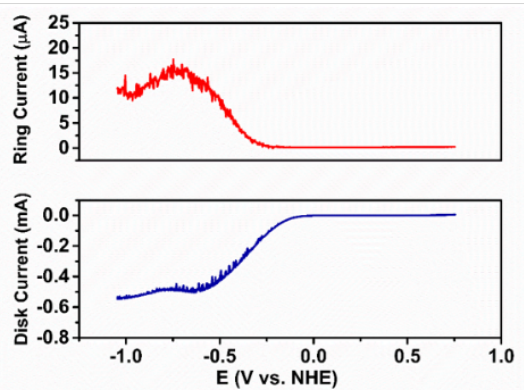

$1 \mathrm{mM}$ MelM
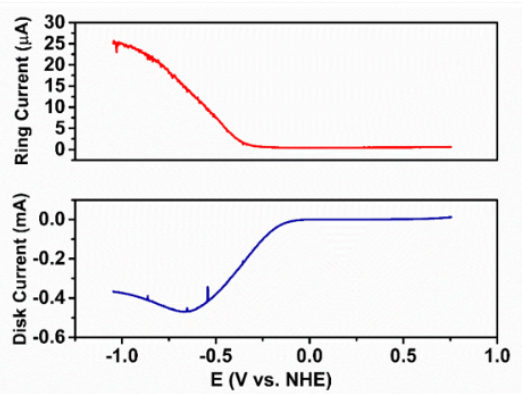

$0.2 \mathrm{mM}$ MelM
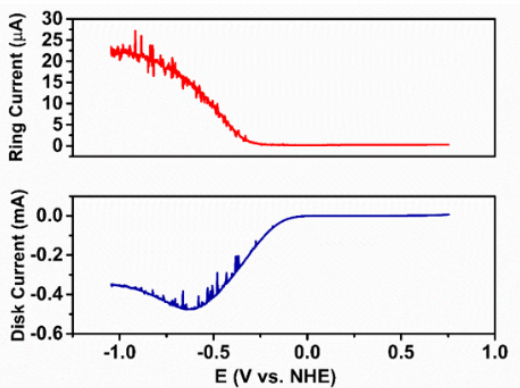

2 mM MelM
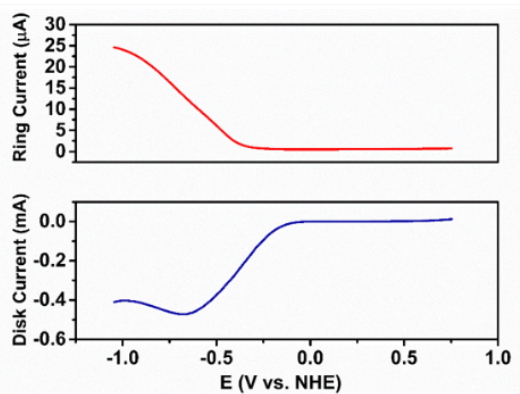

Figure S15. The RRDE experiments for the ORR with UIO-66 at different MeIM concentrations in the oxygen atmosphere. The disk potential was linearly scanned in the cathodic direction from $0.75 \mathrm{~V}$ to $-1 \mathrm{~V}$ (vs NHE) at $5 \mathrm{mV} / \mathrm{s}$ scan rate, while the ring potential was held constant at $0.75 \mathrm{~V}$ (vs NHE) to collect the $\mathrm{H}_{2} \mathrm{O}_{2}$ product.
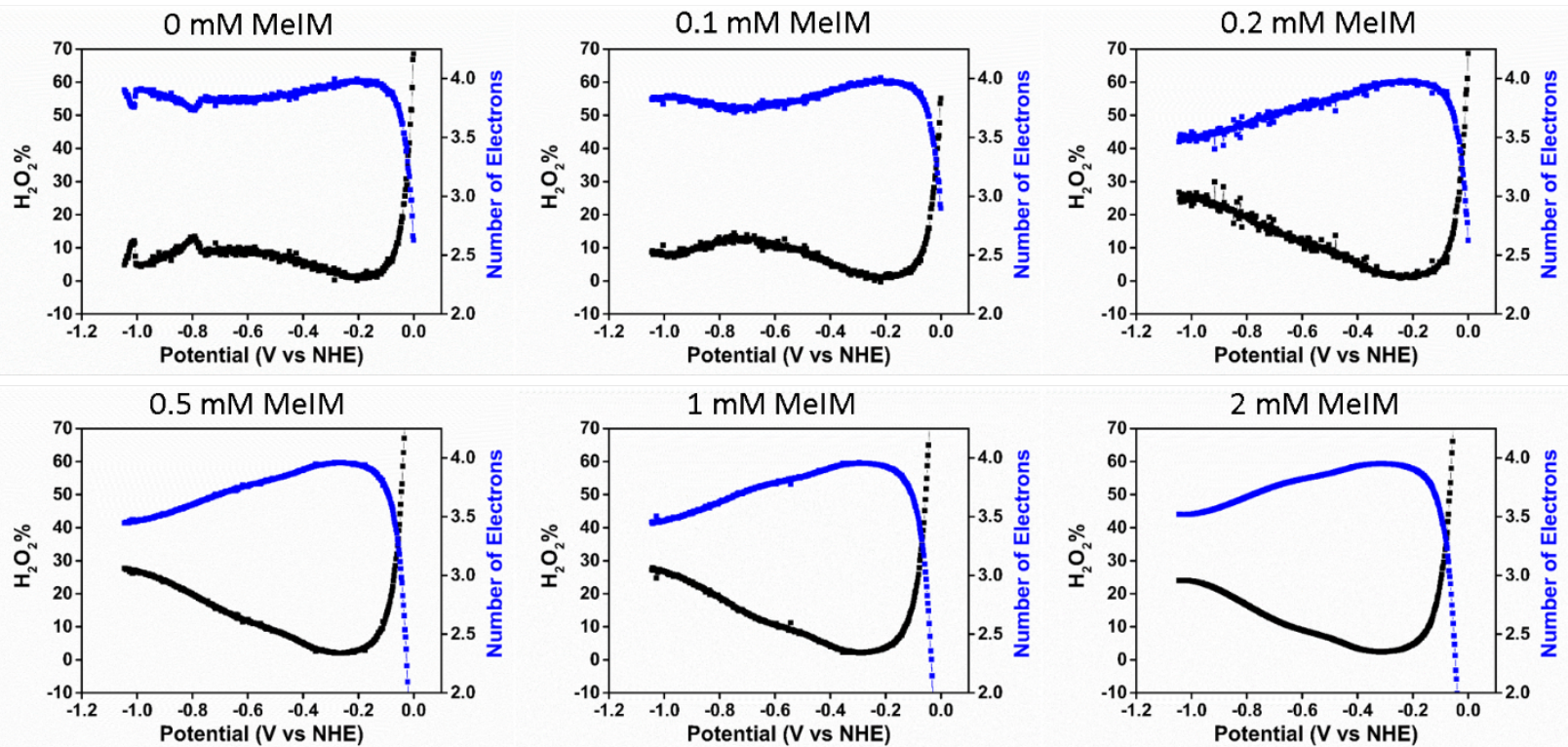

Figure S16. The calculated number of the transferred electrons (blue) and the $\mathrm{H}_{2} \mathrm{O}_{2}$ percentages (black) for in ORR experiments with bare UIO-66 in different MeIM concentrations, elucidated from the RRDE results. 
a)

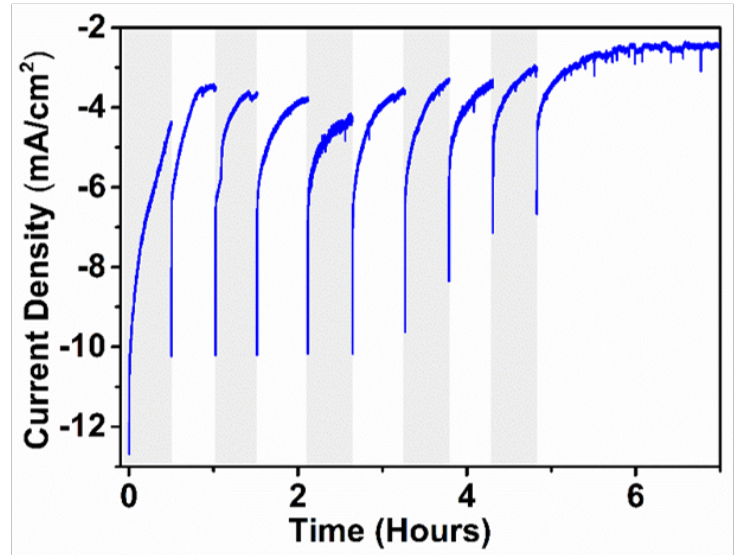

c)

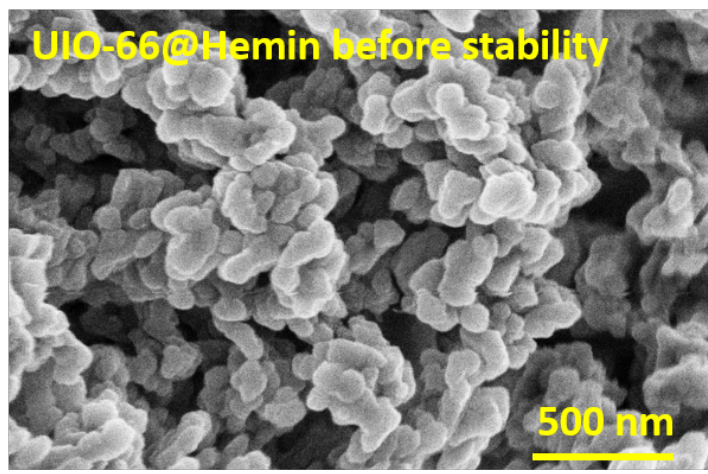

b)

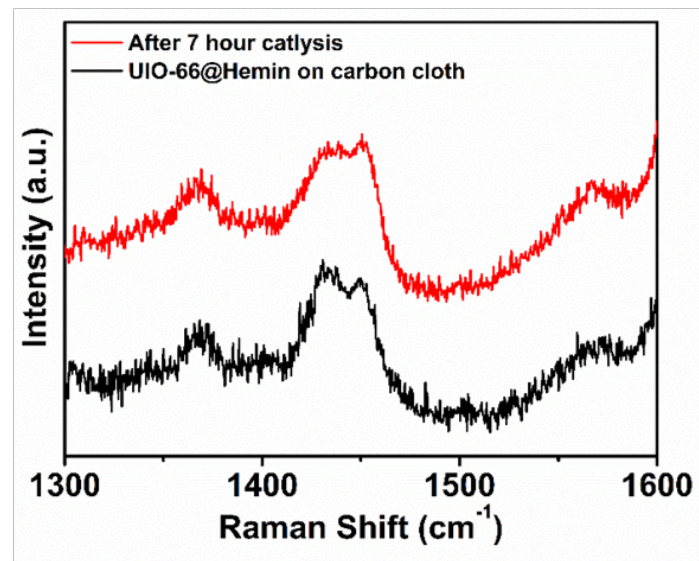

d)

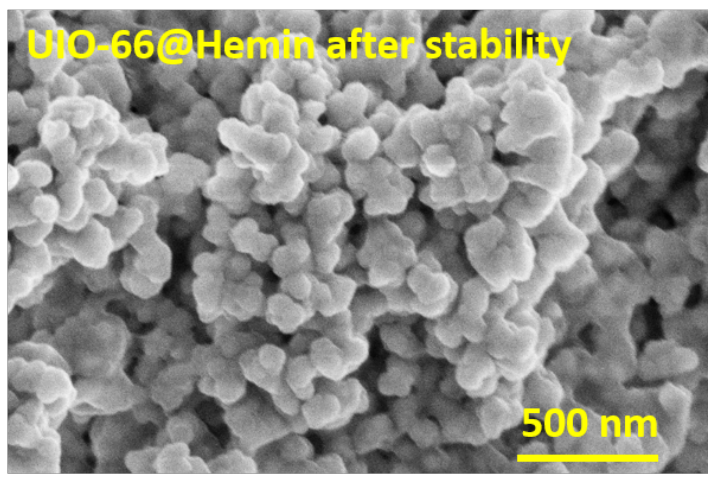

Figure S17. a) Electrolysis stability test for UIO-66@Hemin via chrono-amperometric measurement at -o.45 V vs NHE, with $2 \mathrm{mM}$ of MeIM. Conditions: 9 cycles of 30 min each and one last cycle of 2 hours, with a 10 min $\mathrm{O}_{2}$ purging period between each cycle; b) Raman spectra of UIO-66 before (black) and after (red) stability test; c) SEM of UIO-66@Hemin before stability test and d) SEM of UIO-66@Hemin after the stability test. 


\begin{tabular}{|c|c|c|c|c|c|c|}
\hline & \multicolumn{3}{|c|}{ MelM= 0 mM } & \multicolumn{3}{c|}{ MelM= $\mathrm{mM}$} \\
\hline Potential [V] & Intercept [A-1] & $\mathrm{K}_{\text {cat }}\left[\mathrm{s}^{-1}\right]$ & $\mathbf{k}_{\text {cat }}^{\prime}\left[\mathrm{s}^{-1} \mathbf{M}^{-1}\right]$ & Intercept $\left[\mathrm{A}^{-1}\right]$ & $\mathrm{K}_{\text {cat }}\left[\mathrm{s}^{-1}\right]$ & $\mathbf{k}_{\text {cat }}^{\prime}\left[\mathrm{s}^{-1} \mathbf{M}^{-1}\right]$ \\
\hline-0.144 & 2981 & 0.09 & 58.89 & 1056 & 0.25 & 166.31 \\
\hline-0.244 & 1236 & 0.21 & 142.04 & 786 & 0.33 & 223.23 \\
\hline-0.344 & 757 & 0.35 & 231.92 & 584 & 0.45 & 300.75 \\
\hline-0.444 & 594 & 0.44 & 295.56 & 473 & 0.56 & 371.36 \\
\hline-0.494 & 519 & 0.51 & 338.27 & 406 & 0.65 & 432.69 \\
\hline-0.544 & 456 & 0.58 & 385.00 & 360 & 0.73 & 487.89 \\
\hline-0.594 & 444 & 0.59 & 395.41 & 331 & 0.79 & 529.82 \\
\hline-0.644 & 485 & 0.54 & 361.98 & 318 & 0.83 & 552.65 \\
\hline-0.694 & 534 & 0.49 & 328.77 & 316 & 0.83 & 555.56 \\
\hline-0.744 & 582 & 0.45 & 301.65 & 330 & 0.80 & 531.28 \\
\hline
\end{tabular}

Table S3. The Koutecky-Levich curve intercepts and the correlated kinetic constants $\left(k_{\text {cat }}\right.$ and $k$ ) calculated at different potentials for UIO-66@Hemin without and with 2 mM of MeIM.

\section{References:}

1. Pavlishchuk, V. V.; Addison, A. W., Conversion constants for redox potentials measured versus different reference electrodes in acetonitrile solutions at 25 C. Inorg. Chim. Acta 2000, 298 (1), 97-102.

2. Øien, S.; Wragg, D.; Reinsch, H.; Svelle, S.; Bordiga, S.; Lamberti, C.; Lillerud, K. P., Detailed Structure Analysis of Atomic Positions and Defects in Zirconium Metal-Organic Frameworks. Cryst. Growth Des. 2014, 14 (11), 5370-5372.

3. Wei, W.; Zhang, D. M.; Yin, L. H.; Pu, Y. P.; Liu, S. Q., Colorimetric detection of DNA damage by using hemin-graphene nanocomposites. Spectrochim. Acta A 2013, 106, 163-169.

4. Maindan, K.; Li, X.; Yu, J.; Deria, P., Controlling Charge-Transport in Metal-Organic Frameworks: Contribution of Topological and Spin-State Variation on the Iron-Porphyrin Centered Redox Hopping Rate. J. Phys. Chem. B 2019, 123 (41), 8814-8822.

5. Hirst, J.; Wilcox, S. K.; Ai, J.; Moënne-Loccoz, P.; Loehr, T. M.; Goodin, D. B., Replacement of the Axial Histidine Ligand with Imidazole in Cytochrome c Peroxidase. 2. Effects on Heme Coordination and Function. Biochemistry 2001, 40 (5), 1274-1283. 